\title{
Expression and functional role of hepatocyte growth factor and its receptor (c-met) during fetal mouse testis development
}

\author{
G Ricci, A Catizone ${ }^{\mathbf{1}}$ and $\mathbf{M}$ Galdieri \\ Histology and Embryology Laboratory, Department of Experimental Medicine, School of Medicine, Second University of Naples, Naples, Italy \\ ${ }^{1}$ Department of Histology and Medical Embryology, School of Medicine, University of Rome 'La Sapienza', Rome, Italy \\ (Requests for offprints should be addressed to M. Galdieri; Email: michela.galdieri@uniroma1.it)
}

\begin{abstract}
The hepatocyte growth factor (HGF) is a pleiotropic cytokine able to regulate different cellular functions. HGF action is mediated by its receptor, c-met, a glycoprotein with tyrosine kinase activity. We previously demonstrated that c-met is expressed in the newly formed seminiferous cords of the mice embryonic testes and that HGF acts as a morphogenetic factor. In this paper, we report that at 15.5 days post-coitum (dpc) c-met is expressed in the testicular cords, whereas at $18 \cdot 5 \mathrm{dpc}$ c-met expression is almost exclusively localized in the interstitial tissue of the testis in particular in the fetal Leydig cells. In addition, we demonstrate that HGF gene is expressed during the fetal period of testis development, heavily detectable in the interstitial compartment of $18.5 \mathrm{dpc}$ testes. Interestingly, HGF is not expressed in the Leydig cells

that, as above reported, express the HGF receptor. Looking for the functional role of HGF on Leydig cells, we evaluated the amount of testosterone secreted by testes isolated from $18.5 \mathrm{dpc}$ embryos and cultured in the presence of HGF. The results of the in vitro organ culture show that, at this age, HGF increases the amount of testosterone secreted in the culture medium. On the contrary, HGF does not modulate the amount of testosterone secreted by testes isolated from 15.5 dpc embryos. In conclusion, we report that HGF is produced in the interstitial compartment of the developing testis but not by the Leydig cells. Conversely, the HGF receptor c-met is expressed in the Leydig cells and HGF modulates Leydig cell function during the late period of prenatal development.

Journal of Endocrinology (2006) 191, 559-570
\end{abstract}

\section{Introduction}

Organogenesis of the mammalian gonad is a highly coordinated process that in the male is determined by the activation of the sex-determining gene Sry which induces a series of events necessary for the organogenesis of the testis. After Sry activation, cells at the coelomic surface of the XY gonad actively proliferate to increase the number of Sertoli cell precursors (Karl \& Capel 1998) and migration of cells from the adjacent mesonephros occurs. As clearly demonstrated, in mammals mesonephric cell migration is a crucial event for the morphogenesis of the testis (Buehr et al. 1993, Martineau et al. 1997, Capel et al. 1999, Tilmann \& Capel 1999, Uzumcu et al. 2002, Brennan et al. 2003, Jeays-Ward et al. 2003). In mice, seminiferous cord formation is the morphogenetic event characterizing testis differentiation at 12.5 days post-coitum (dpc) and very little is known of the molecular mechanisms underlying testis organogenesis. Several growth factors are involved in embryonic testicular differentiation such as transforming growth factors (Olaso et al. 1998, Cupp et al. 1999a,b, Levine et al. 2000), neurotrophins (Cupp et al. 2000, 2002) and insulin (Nef et al. 2003) and we have reported the involvement of an isoform of platelet-derived growth factor (PDGF-BB) in testis cord organization this factor being able to support testicular cord formation in vitro (Ricci et al. 1999, 2004). In a recent paper we have shown, in parallel with other authors, that $\alpha$ and $\beta$ subunits of the platelet-derived growth factor receptors (PDGFR) are expressed in the differentiating male urogenital ridges and that PDGF-BB is synthesized and secreted by the testis during its embryonic differentiation (Puglianiello et al. 2004, Ricci et al. 2004). In addition, we have demonstrated that PDGF-BB induces mesonephric cells migration and modulates the functional activities of the testicular cells increasing testicular cell proliferation and reorganizing dissociated testicular cells into large cellular aggregates (Ricci et al. 2004). PDGFs are also involved in the differentiation of embryonic Leydig cells: Brennan and co-workers (2003), using PDGFR $\alpha$ knock-out embryos, have reported a sex-specific role for PDGFR $\alpha$ in promoting cord formation, proliferation, mesonephric cell migration, and fetal Leydig cell differentiation. In a previous paper, similar effects have been described for Desert hedgehog (DHH), a signaling molecule secreted by the Sertoli cells, which is the only other factor reported as a modulator of the embryonic Leydig cell differentiation (Yao et al. 2002). Beside 
PDGF-BB, we have previously reported that the hepatocyte growth factor (HGF) is highly involved in testicular differentiation as demonstrated by our in vitro experiments showing that undifferentiated gonadal ridges cultured in a chemically defined medium supplemented with HGF alone differentiate in culture in a way comparable with that of gonads cultured in the presence of serum (Ricci et al. 1999, 2002). In both experimental conditions after 3 days of culture, cord-like structures were well visible in the male gonads. In the gonads cultured in the presence of PDGF-BB alone a morphological differentiation occurs; however the size of the newly formed cords was small and our experiments of reaggregation performed culturing dissociated testicular cells in the presence of HGF or PDGF-BB indicated that cord-like structures were formed in culture exclusively when HGF was supplemented to the culture medium (Ricci et al. 2004).

In the present paper, we have studied the expression of HGF and its receptor, c-met, during the late period of the testicular prenatal development. We report that the factor is expressed in the interstitial compartment of the testis but not in the Leydig cells. Moreover, we report that the HGF receptor expression is differently regulated during testis development being highly expressed in the cords at 15.5 $\mathrm{dpc}$ and almost exclusively expressed in the interstitial tissue at $18.5 \mathrm{dpc}$. At $18.5 \mathrm{dpc}$, Leydig cells express c-met and their testosterone secretion is increased by the factor.

\section{Materials and Methods}

\section{Animals}

CD-1 mice embryos were used for the experiments. Pregnant mice were housed at the University of Rome 'La Sapienza'. All animal studies were conducted in accordance with the principles and procedures outlined in the National Institute of Health (NIH) Guide for Care and Use of Laboratory Animals and killed by $\mathrm{CO}_{2}$ asphyxia. For determination of the age of the embryos, the morning after vaginal plug formation was considered as day 0.5 of embryonic development.

\section{RNA isolation and northern blot analysis}

Various tissues from embryonic CD-1 mice were dissected and RNA was extracted according to the method of Chomczynski \& Sacchi (1987). The integrity of the RNA was tested through the presence of the ribosomal species in formaldehyde denaturing gels. Northern blot analysis using $30 \mu \mathrm{g}$ RNA in each lane was performed on $1 \%$ agarose/ formaldehyde gels and transferred to Hybond-N+ membrane (Amersham-Italia). Prehybridization, hybridization, and washings were performed according to the conditions suggested by the supplier. The membranes were exposed for 3 days with Kodak Biomax MS X-ray films and intensifying screens. Mouse met and HGF cDNA (kindly provided by Dr C Ponzetto, Torino University, Torino, Italy) was labeled using a random primer labeling kit (Gibco BRL, Life Technologies). C-met expression in total RNA was normalized to the signal for the constitutively expressed glyceraldeyde-3-phosphate dehydrogenase.

\section{RT-PCR analysis}

Total RNA was extracted as above described. To reduce contamination by genomic DNA, total RNAs were treated with ribonuclease-free DNase I Amplification grade as recommended by the manufacturer (Invitrogen). Samples of total RNAs $(1 \mu \mathrm{g})$ were reverse transcribed with reverse transcriptase (RT) using $200 \mathrm{U}$ cloned M-MLV RT (Invitrogen) in the presence of $500 \mu \mathrm{g} / \mu$ l oligo dT primers and $2 \mathrm{mM}$ deoxyNTP at $37^{\circ} \mathrm{C}$ for $50 \mathrm{~min}$, and the reaction was terminated by heating at $70^{\circ} \mathrm{C}$ for $15 \mathrm{~min}$. PCR was performed utilizing the Hotmaster Taq DNA polymerase (Eppendorf s.r.l., Milano, Italy) and the following primers: c-Met sense 5'-CTGAAGGAAACCCAAGATG-3', antisense $5^{\prime}$-AAACACCCCGAAGAGAATG-3', HGF sense $5^{\prime}$-GCTACACTCTTGACCCTGACA-3' , antisense $5^{\prime}$-GTTTTTCCCATTGCCACGAT- $3^{\prime}$, $\beta$-actin sense $5^{\prime}$-TGTGATGGTGGGAATGGGTCAGAA-3', antisense $5^{\prime}$-GCTTCTCTTTGATGTCACGCACGATT- $3^{\prime}$. To determine the number of cycles required for each gene, preliminary reactions were performed using different amplification cycles to ascertain that amplification was in the logarithmic linear phase. The amplification program consisted of a first denaturing cycle at $94{ }^{\circ} \mathrm{C}$ for 5 min followed by cycles of the following steps: 30 cycles of amplification (25 for $\beta$-actin) defined by denaturation at $94{ }^{\circ} \mathrm{C}$ for $30 \mathrm{~s}$, annealing at $52{ }^{\circ} \mathrm{C}$ (c-met) or $55^{\circ} \mathrm{C}$ (HGF) or $63{ }^{\circ} \mathrm{C}$ ( $\beta$-actin) for $35 \mathrm{~s}$, and extension at $72^{\circ} \mathrm{C}$ for $40 \mathrm{~s}$. The final incubation was performed at $72{ }^{\circ} \mathrm{C}$ for $5 \mathrm{~min}$. PCR products were separated by $2 \%$ agarose gel electrophoresis and visualized by ethidium bromide staining. Quantification of the intensity of RT-PCR signals was performed by densitometry scanning using an image analysis system (Raytest, DIANA detection system equipped with Advanced Image Data Analyzer software). To assure equal synthesis of cDNA in different samples, $\beta$-actin was used as a standard. The values reported represent a ratio between the expression levels of sample gene/ $\beta$-actin gene. Forty nanograms of the purified RT-PCR products were utilized for a sequence analysis automatically performed using ABI Prism 377-96 (Sanger method).

\section{Whole mount in situ hybridization}

In situ hybridization was performed on embryonic testes fixed by overnight immersion in 4\% paraformaldehyde (PFA) in PBS ( $\mathrm{pH} \mathrm{7.4),} \mathrm{at} 4^{\circ} \mathrm{C}$ and washed twice in PBS for $1 \mathrm{~h}$. The samples were treated with proteinase $\mathrm{K}$ $10 \mu \mathrm{g} / \mathrm{ml}$ in PBS containing $0 \cdot 1 \%$ Tween for $10-20 \mathrm{~min}$ at room temperature. Antisense and sense riboprobes were generated to the mouse c-met c-DNA, subcloned in Bluescript II Sk by in vitro transcription by $\mathrm{T} 3$ and $\mathrm{T} 7$ 
A
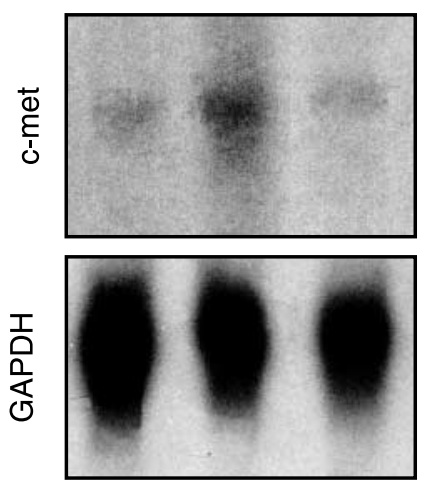

$\mathrm{Li}$
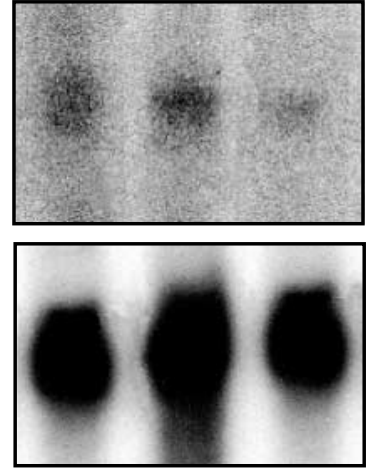

$\mathrm{Li}$

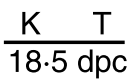

C

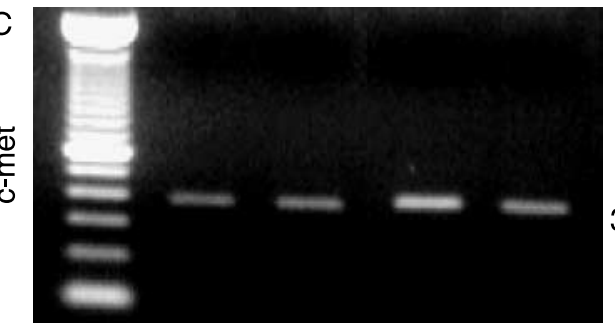

$384 \mathrm{bp}$

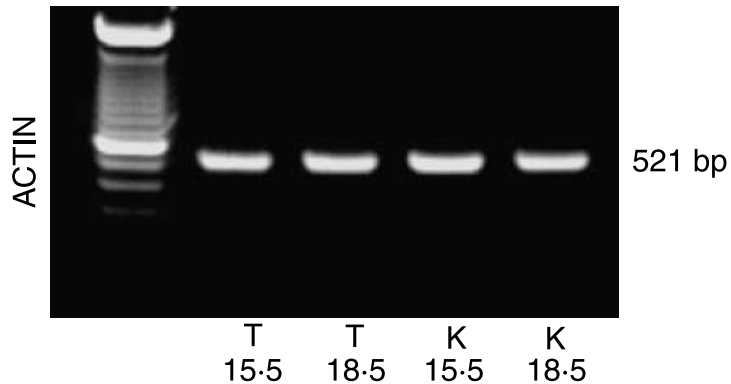

D

c-met

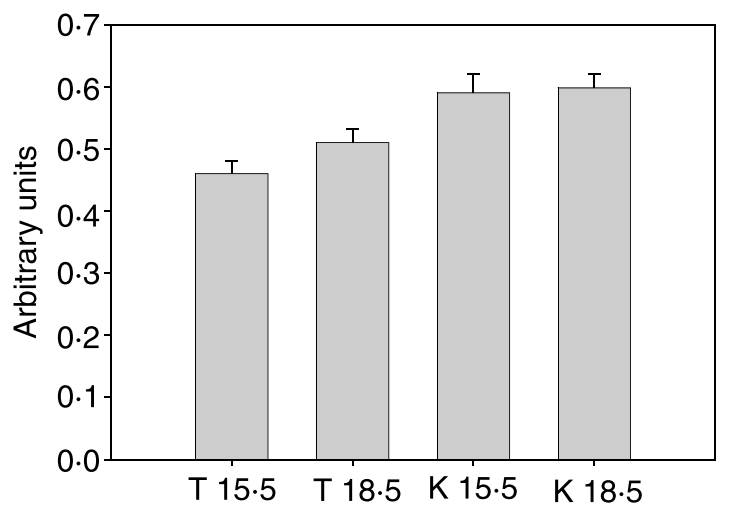

Figure 1 Expression of c-met mRNA in the developing male gonad. (A) Northern blot analysis was performed on $30 \mu \mathrm{g}$ total RNA extracted from the different organs at 15.5 and $18.5 \mathrm{dpc}$. K, kidney; T, testis; Li, liver (prepuberal mice). X-ray films were exposed for 3 days with Kodak Biomax MS films and intensifying screens. The results of one representative experiment of the three, each performed in duplicate are reported. The densitometry of northern blots is presented and the mean \pm s.E.M. of the three experiments performed is reported in (B). RT-PCR analysis of the RNAs isolated from the same organs used in the northern blots is shown in (C). The results of one representative experiment of the three, each performed in duplicate are reported. In (D), the densitometry of RT-PCRs is presented as means \pm S.E.M. of the three experiments performed. The significance of the results was determined by using the Student's $t$-test.

RNA polymerase in the presence of digoxigenin-labeled UTP following the manufacturer's instructions. Probes were diluted in hybridization $\operatorname{mix}$ at $1 \mu \mathrm{g} / \mathrm{ml}$ and $1 \mathrm{ml}$ hybridization mix was applied to the samples. Detection of c-met mRNA by whole mount in situ hybridization was carried out according to Wilkinson \& Nieto (1993). The hybrids bound to alkaline phosphatase-conjugated antidigoxigenin antibody were visualized by a color reaction mixture containing 1\% Tween-20, 2 mM Levamisole in BM purple AP substrate (Boehringer, Mannheim, Germany), and color was allowed to develop for $3-5 \mathrm{~h}$ in the dark. The reaction was stopped by incubation with PBS, $0 \cdot 1 \%$
Tween-20, $10 \mathrm{mM}$ EDTA for $10 \mathrm{~min}$. Samples were fixed with $4 \%$ formaldehyde in PBS overnight at $4{ }^{\circ} \mathrm{C}$ and stored in PBS containing $0 \cdot 1 \%$ sodium azide at $4{ }^{\circ} \mathrm{C}$. For sectioning, the samples were maintained in $\mathrm{PBS}, 7 \%$ sucrose for $5-10 \mathrm{~min}$ at $4{ }^{\circ} \mathrm{C}$ and than in PBS, $15 \%$ sucrose for 5$10 \mathrm{~min}$ at $4{ }^{\circ} \mathrm{C}$; successively the samples were maintained in PBS, $15 \%$ sucrose, $7 \%$ gelatin at $37^{\circ} \mathrm{C}$ to achieve the complete embedding of the samples. The samples were then included in the latter solution, which is solid at room temperature, and frozen in liquid nitrogen. The samples were sectioned, viewed, and photographed by a light microscope (Zeiss Axioplan, Hallbergmoos, Germany). 

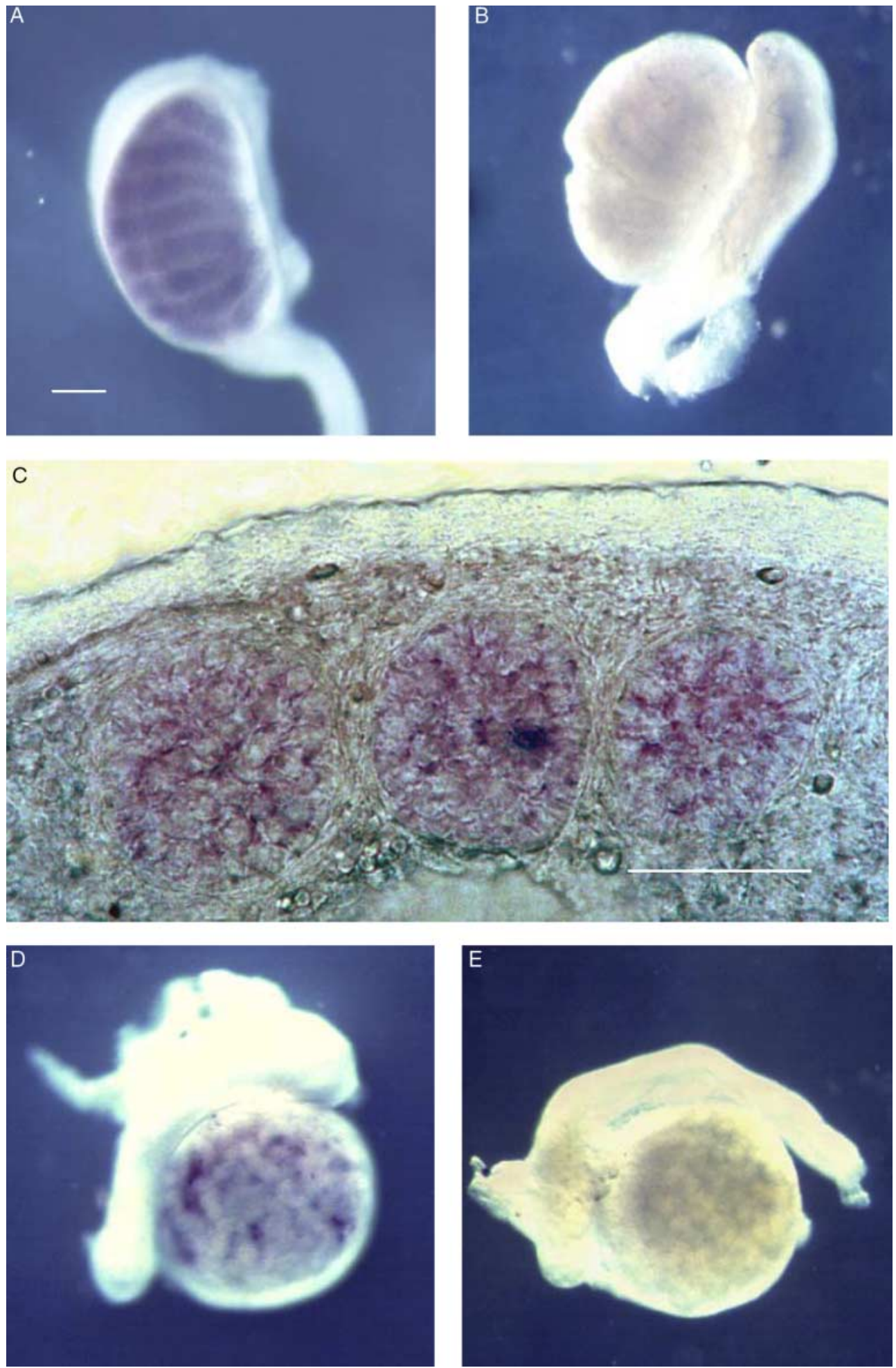

Figure 2 (continued) 


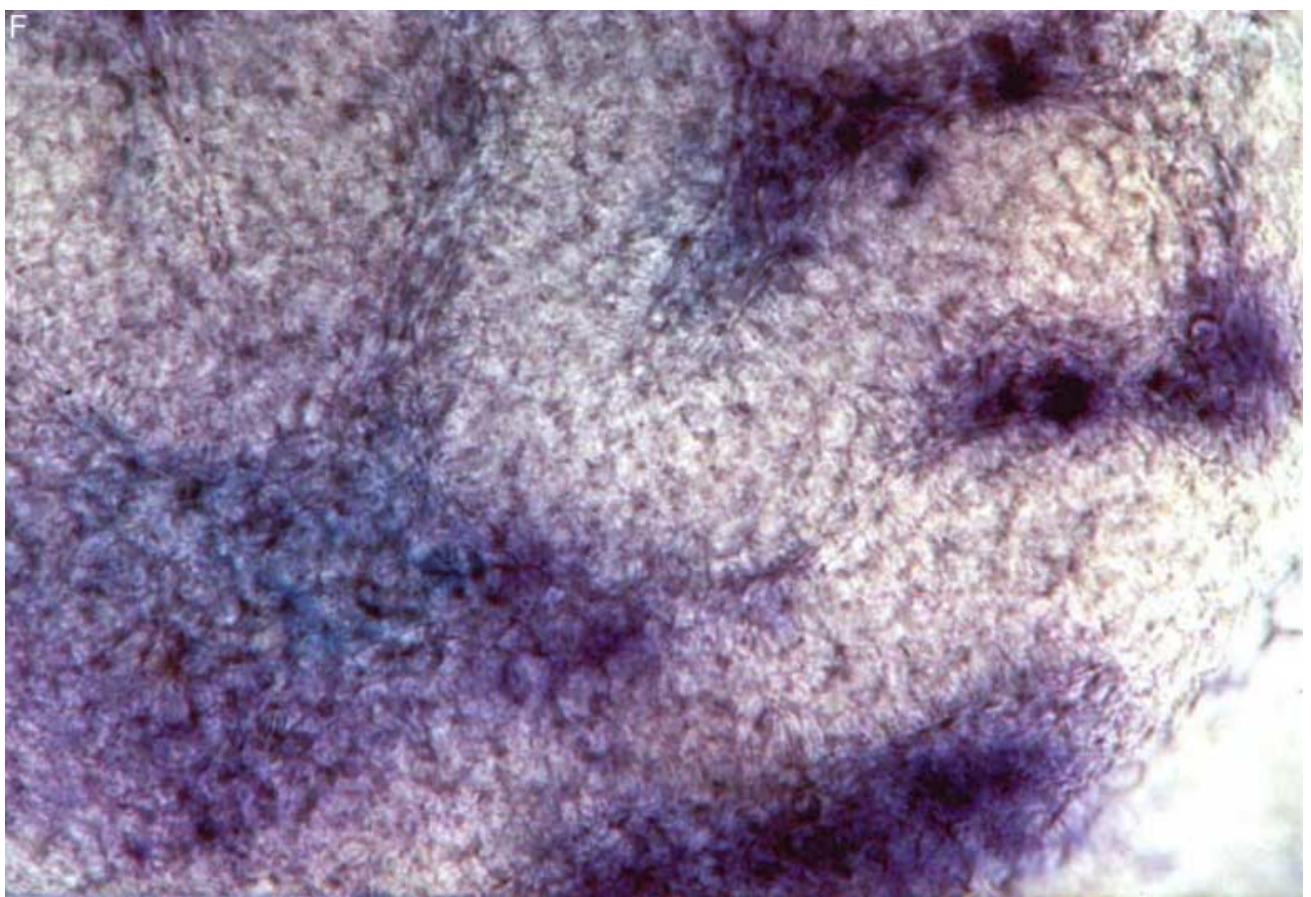

Figure 2 Whole mount in situ hybridization of c-met expression during testis development. (A), 15.5 dpc; (D), $18.5 \mathrm{dpc}$. The hybridizations with the sense probe at the same ages ( $\mathrm{B}, \mathrm{E}$ respectively) are reported. Bar, $185 \mu \mathrm{m}$. (C), transverse section of testis isolated from 15.5 dpc embryo. (F), transverse section of testis isolated from 18.5 dpc embryo. Bar, $95 \mu \mathrm{m}$. The results of one representative experiment of the three, each performed analyzing six testes, are reported.

Immunolocalization of HGF, c-met, relaxin, and $3 \beta$-hydroxysteroid dehydrogenase

Testes isolated from $15 \cdot 5$ and $18 \cdot 5 \mathrm{dpc}$ embryos were fixed overnight in PFA 4\% (for HGF and 3 $\beta$-hydroxysteroid dehydrogenase (3ß-HSD) localization) or Bouin's solution (for c-met and relaxin localization). Samples were then dehydrated, embedded in paraffin, and sectioned at a thickness of 5 or $2.5 \mu \mathrm{m}$ (serial sections). Sections were dewaxed, hydrated, and rinsed with PBS. Endogenous peroxidases were blocked by incubation with $3 \%$ hydrogen peroxide in PBS for $20 \mathrm{~min}$ at room temperature. The primary antibody against c-met was from Santa Cruz Biotechnologies (Santa Cruz, CA, USA; SP-260; 1:20 dilution), the anti-relaxin antibody (raised in rabbit; 1:1500 dilution) was kindly provided by Dr R Ivell (Hamburg, Germany), and the anti-type I $3 \beta$-HSD (raised in rabbit, 1:2000 dilution) was kindly provided by Dr J I Mason (University of Edinburgh, Edinburgh, UK). The primary antibody against human-HGF (DV-14 monoclonal antibody) was kindly provided by Dr M Prat (Piemonte Orientale University, Prat, Italy) and used as previously described (Ricci et al. 2002). Sections were incubated with the primary antibodies overnight at $4{ }^{\circ} \mathrm{C}$. The following steps of the immunolocalization were performed according to the manufacturer's instructions (Histostain-Plus kit; Zymed Laboratories, San Francisco, CA, USA). The avidin-biotin immunoperoxidase system with 3,3-diaminobenzedine (Amersham-Italia) as chromogen was used to visualize bound antibodies. The preparations were counterstained with hemalum, dehydrated, mounted with Histovitrex (Carlo Erba, Milan, Italy), and analyzed using a Zeiss Axioscope. Negative controls were processed in the absence of the primary antibody.

For double immunolocalization of HGF and $3 \beta-H S D$, a Leica confocal microscope (Laser Scanning TCS SP2) equipped with $\mathrm{Ar} / \mathrm{ArKr}$ and $\mathrm{HeNe}$ lasers was utilized. To detect DV-14 antibody, a FITC-conjugated goat anti-mouse secondary antibody (1:50; Sigma) was used, whereas for $3 \beta-$ HSD detection, a CY3-conjugated donkey anti-rabbit secondary antibody (1:400; Jackson Laboratories, Bar Harbor, Maine, USA) was used. Human recombinant HGF was purchased from Sigma-Aldrich Chemical Co. (H1404) and utilized to block DV-14 antibody (tenfold excess). The images were acquired utilizing the Leica confocal software.

\section{Organ culture and testosterone evaluation}

The testes were isolated from $15 \cdot 5$ and $18 \cdot 5 \mathrm{dpc}$ male embryos and cultured on steel grids (four testes/grid) previously coated 
with $2 \%$ agar. Grids were then placed in organ culture dishes (Falcon, Franklin Lakes, NJ, USA) with $0.8 \mathrm{ml}$ medium necessary to wet the grid. The chemically defined medium utilized was Dulbecco's modified Eagle's medium (Gibco) supplemented with glutamine $(2 \mathrm{mM})$, Hepes $(15 \mathrm{mM})$, non essential amino acids, penicillin (100 IU $/ \mathrm{ml})$, and streptomycin $(100 \mu \mathrm{g} / \mathrm{ml})$. HGF (Sigma-Aldrich Chemical Co., $\mathrm{H} 1404,50-200 \mathrm{U} / \mathrm{ml}$ ) was added to the culture medium when indicated. The neutralizing antibody against HGF (Sigma-Aldrich Chemical Co., H7157) was utilized as indicated by the manufacturer. Testes were cultured for $24 \mathrm{~h}$ at $37^{\circ} \mathrm{C}$ in a humidified atmosphere of $5 \% \mathrm{CO}_{2}$ in air. After culture, conditioned culture medium was utilized for testosterone determination by RIA utilizing the 'Access' immunoassay system commercialized by the Beckman Coulter Inc. (Fullerton, CA, USA).

\section{Statistical analysis}

Data were analyzed using SigmaPlot 8.0 software package (Systat Software, San Jose; CA, USA). Student's $t$-test was employed.

\section{Results}

Expression of HGF receptor (c-met) $m R N A$ in developing gonads

Northern blot and RT-PCR analysis We studied the temporal expression pattern of c-met during the late period of male gonad development. Testes from 15.5 to $18 \cdot 5 \mathrm{dpc}$ embryos were isolated and total RNAs were extracted. RNA was also extracted from kidney from 15.5 to $18.5 \mathrm{dpc}$ embryos. As shown in Fig. 1A, the presence of one c-metspecific transcript was detected by northern blot in the RNAs extracted from embryonic testes of the different ages. The size of the detected mRNA species is estimated to be $9 \mathrm{~Kb}$ since it is coincident with the single mRNA species detectable in the postnatal liver RNA (Li). In Fig. 1B, the densitometric scanning of the bands obtained in the three experiments performed is reported. The densitometric scanning of the bands obtained in the three experiments performed indicates no changes in c-met mRNA levels in the testes during development. In Fig. 1C, the RT-PCR analysis is shown. One transcript was detected upon RT-PCR (384 bp) in all the samples analyzed. In the RT-PCR samples in which the RT was omitted, no signals were detected (not shown). In Fig. 1D, the densitometric scanning of the bands obtained in the three experiments performed is reported. Also utilizing this technique, no significant differences in c-met expression levels were detected. The product of the RT-PCR was sequenced and the sequence fully recognizes the Mus musculus c-met cDNA (g.i. 6678867 NCBI gene bank).
In situ hybridization experiments Testes were isolated from embryos at 15.5 and $18.5 \mathrm{dpc}$ and, by whole mount in situ hybridization experiments, c-met expression was evaluated. At $15.5 \mathrm{dpc}$ c-met expression was clearly detectable in the testicular cords (Fig. 2A) and a faint expression was detected at $15.5 \mathrm{dpc}$ outside the cords (Fig. 2A). On the contrary, at $18.5 \mathrm{dpc}$ c-met expression was essentially localized in the interstitial portion of the testis (Fig. 2D), whereas very low expression levels were found in the testicular cords (Fig. 2D). Control samples obtained utilizing a sense probe (Fig. 2B and E respectively) did not give detectable signals. Hybridized samples were embedded in gelatin and sectioned to better look at the internal morphology and labeling localization. Figure $2 \mathrm{C}$ shows a section of $15.5 \mathrm{dpc}$ testis in which the 'tunica albuginea' appears to be unlabeled, whereas the interstitial tissue appears to be faintly labeled and very positive signals are present in the cords. Figure $2 \mathrm{~F}$ confirms that at $18.5 \mathrm{dpc}$, the labeling is essentially localized in the interstitial tissue. A similar localization was found in the testes isolated from newborn animals (not shown).

Relaxin and c-met localization To evaluate if fetal Leydig cells are c-met-positive, the expression of relaxin and c-met was evaluated by immunohistochemistry in serial sections of $18.5 \mathrm{dpc}$ testes. As shown in Fig. 3 in the interstitial tissue large cells, stained for c-met (A) and relaxin (B) are present. The morphology of the cells and their staining both for c-met and relaxin allow us to conclude that fetal Leydig cells express the HGF receptor (arrows).

\section{Expression of HGF in developing gonads}

Northern blot and RT-PCR analysis The expression pattern of HGF mRNA during late male gonad development was also studied. Testes from embryos at 15.5 and $18.5 \mathrm{dpc}$ were isolated and total RNAs extracted. The presence of one HGF-specific transcript was detected by northern blot in the RNAs extracted from embryonic testes of the different ages (Fig. 4A) as well as in the other tissues studied. The molecular weight of the detected mRNA species is estimated to be $6 \mathrm{~Kb}$ since it is coincident with the single mRNA species detectable in the postnatal liver RNA (Li). In Fig. 4B, the densitometric scanning of the bands obtained in the three experiments performed is reported. In Fig. 4C, the RT-PCR analysis is shown. One transcript was detected upon RT-PCR (383 bp) in all the samples analyzed. In the RT-PCR samples in which the RT was omitted, no signals were detected (not shown). In Fig. 4D, the densitometric scanning of the bands obtained in the three experiments performed is reported. Utilizing the two different techniques, a significant increase in expression levels of HGF was detected in the testes at $18.5 \mathrm{dpc}$ compared with $15.5 \mathrm{dpc}$ testes. The product of the RT-PCR analysis was sequenced and the sequence fully recognizes the Mus musculus RNA for HGF cDNA (g.i. 433430 NCBI gene bank). 

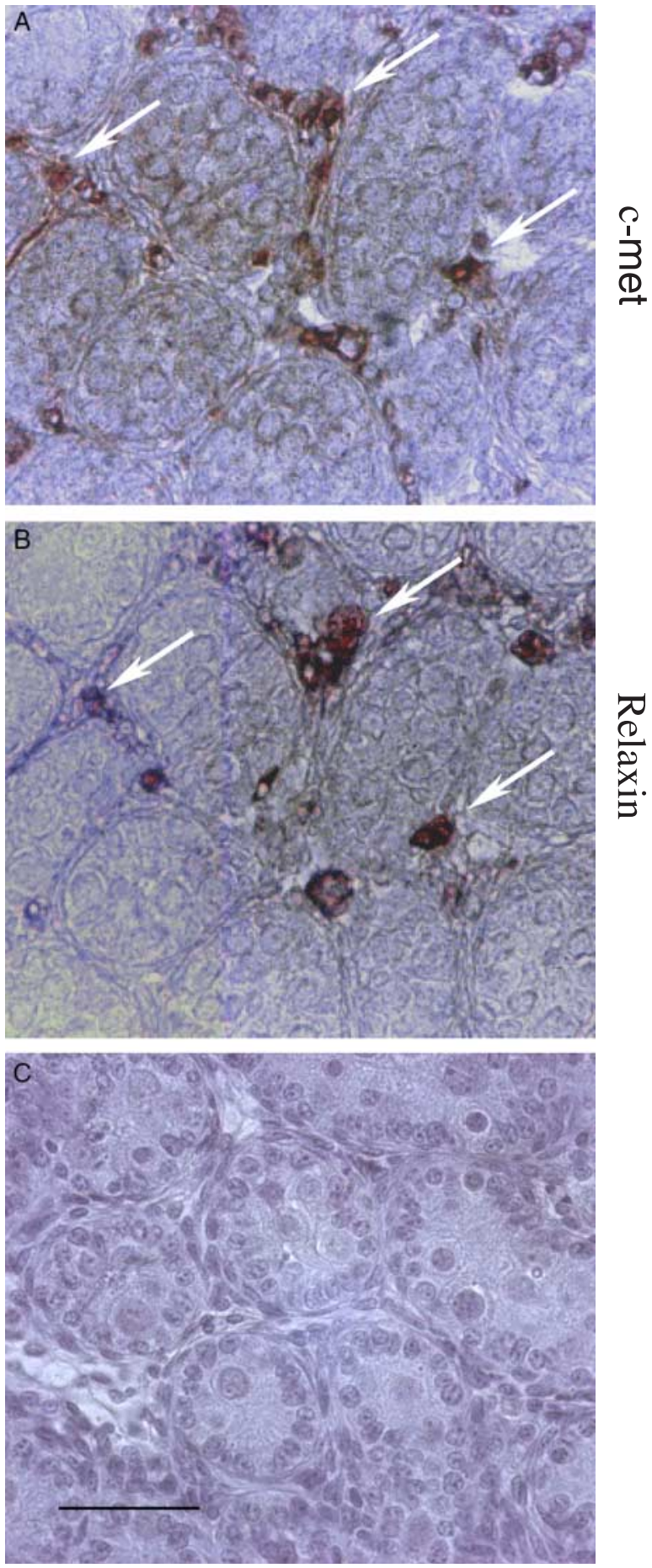

Figure $3 \mathrm{C}$-met and relaxin expression in testes isolated from 18.5 $\mathrm{dpc}$ embryos. The arrows indicate the c-met-positive (A) and relaxin-positive $(B)$ cells. The negative control sections where the primary antibody was excluded from the procedure are presented in (C). Bar $35 \mu \mathrm{m}$. The results of one representative experiment of the three, each performed in duplicate are reported.
Immunolocalization of HGF The presence of the HGF was studied by immunohistochemistry in testes isolated from $15.5 \mathrm{dpc}$ (Fig. 5A) and compared with testes from $18.5 \mathrm{dpc}$ embryos (Fig. 5D). Low and high magnifications of testes of both ages are presented (respectively B, C and E, F) in which the HGF staining is present in the tunica albuginea cells, the interstitial compartment, and the flat peritubular cells in testes isolated both from 15.5 (Fig. 5B and C) and $18.5 \mathrm{dpc}$ embryos (Fig. 5E and F). Negative control sections are also presented (Fig. 5A and D). To evaluate if fetal Leydig cells are HGF-positive, serial sections of 15.5 and $18.5 \mathrm{dpc}$ testes were used to detect HGF (respectively Fig. $5 \mathrm{H}$ and L) and $3 \beta$ HSD positive cells (Fig. 5G and I). The arrows indicate the cells positive for $3 \beta$-HSD, whereas arrowheads indicate the HGF positivity. HGF appears not to be expressed in the Leydig cells that, conversely, highly express $3 \beta$-HSD. In these serial sections, the HGF staining is less evident because of the lower thickness of the sections $(2.5$ instead of $5 \mu \mathrm{m})$. To better detect the HGF localization, testicular sections of $18.5 \mathrm{dpc}$ embryos were used for double localization of HGF (Fig. 6A) and $3 \beta$-HSD (Fig. 6B). The distribution pattern of these two molecules does not overlap (Fig. 6C) clearly showing that Leydig cells do not produce HGF. In 6D, the picture obtained utilizing the anti-HGF antibody previously incubated with the human recombinant HGF is shown. The incubation of the antibody with HGF abolishes almost completely the positive signals and the low residual signals present have to be considered not specific. In $6 \mathrm{E}$, the corresponding bright field is shown.

\section{Testosterone production}

Testes isolated from $18.5 \mathrm{dpc}$ embryos were cultured for $24 \mathrm{~h}$ in medium alone or supplemented with different doses of $\mathrm{HGF}$ ranging from 50 to $200 \mathrm{U} / \mathrm{ml}$. The media were collected for testosterone determination by RIA and the relative amount of testosterone secreted is reported in Fig. 7A. The results obtained in the four different experiments indicate that the amount of testosterone secreted by the testes cultured in the presence of different doses of HGF is significantly higher with respect to the control samples. The highest secretion of testosterone was obtained with the dose of $100 \mathrm{U} / \mathrm{ml}$ and the higher dose $(200 \mathrm{U} / \mathrm{ml})$ did not increase the hormone secretion. The supplementation of the blocking antibody against HGF prevented the increase of testosterone in the samples treated with $100 \mathrm{U} / \mathrm{ml} \mathrm{HGF}$ (Fig. 7A). On the other hand, the secretion of testosterone by testes isolated from $15.5 \mathrm{dpc}$ embryos cultured for $24 \mathrm{~h}$ in medium supplemented with $100 \mathrm{U} / \mathrm{ml} \mathrm{HGF}$ was not modulated by the growth factor (Fig. 7B). We also present the absolute values obtained in one representative experiment performed using testes of 18.5 (Fig. 7C) and $15.5 \mathrm{dpc}$ (Fig. 7D). In our experiments, the absolute values of secreted testosterone in the control samples ranged from 1.7 to $2.7 \mathrm{ng} /$ testis in 


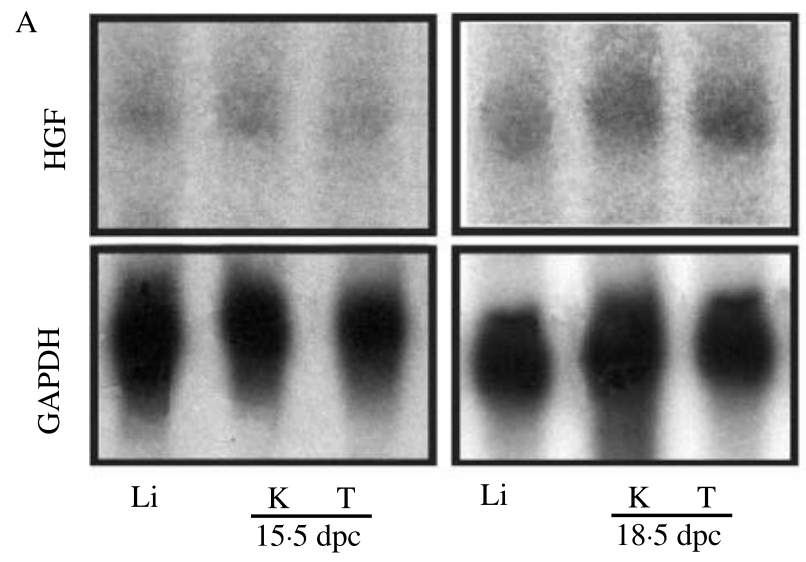

$\mathrm{C}$

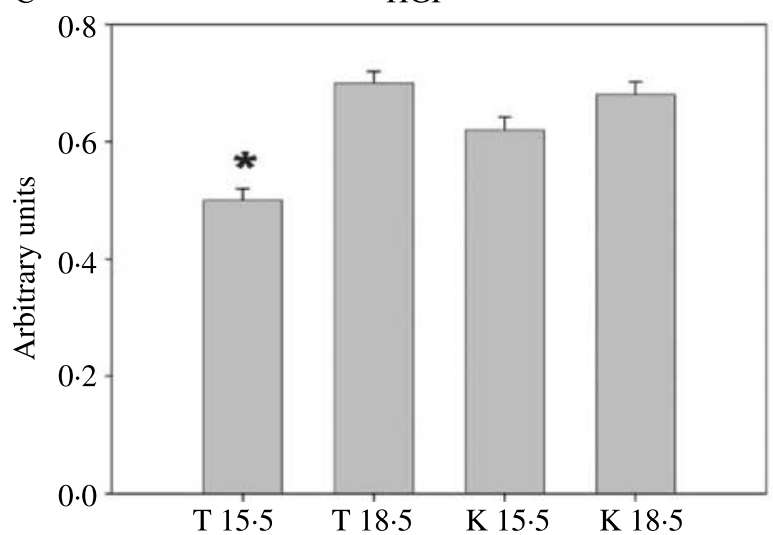

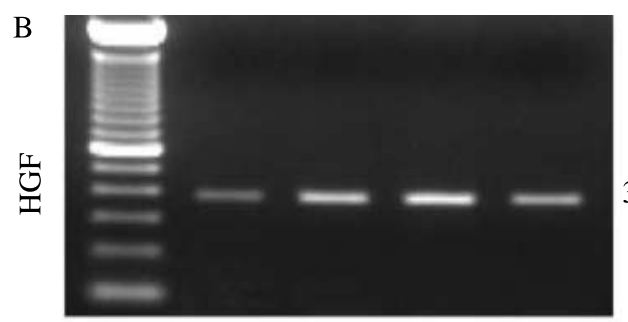

$383 \mathrm{bp}$

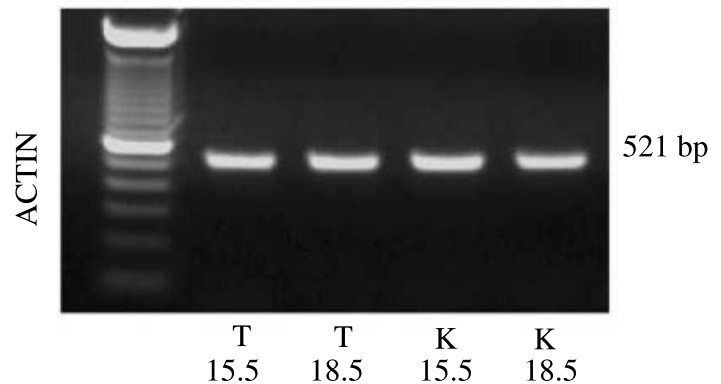

$\mathrm{D}$

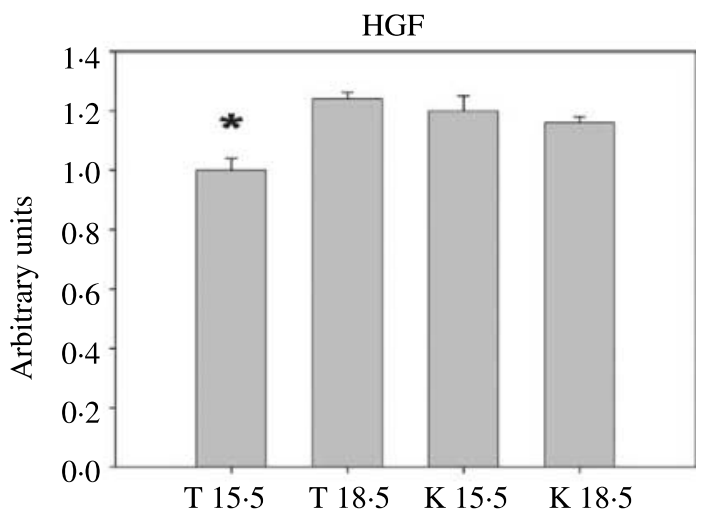

Figure 4 Expression of HGF mRNA in the developing male gonad. (A) Northern blot analysis was performed on $30 \mu \mathrm{g}$ total RNA extracted from the different organs at 15.5 and $18.5 \mathrm{dpc}$. K, kidney; T, testis; Li, liver (prepuberal mice). X-ray films were exposed for 3 days with Kodak Biomax MS films and intensifying screens. The results of one representative experiment of the three, each performed in duplicate are reported. The densitometry of northern blots is presented and the mean \pm S.E.M. of the three experiments performed is reported in (B). RT-PCR analysis of the RNAs isolated from the same organs used in the northern blots is shown in (C). The results of one representative experiment of the three, each performed in duplicate are reported. In (D), the densitometry of RT-PCRs is presented as mean \pm s.E.M. of the three experiments performed. The significance of the results was determined using the Student's $t$-test. ${ }^{*} P<0 \cdot 05$ vs $T 18 \cdot 5$.

the $15.5 \mathrm{dpc}$ cultures and from 0.9 to $2 \cdot 0 \mathrm{ng} /$ testis in the $18 \cdot 5 \mathrm{dpc}$ cultures.

\section{Discussion}

It is well known that HGF and its receptor, c-met, are involved in the development of the embryonic testis. As we previously demonstrated, HGF is able to support in vitro the differentiation of the urogenital ridge, acts as a mitogenic factor for testicular cells isolated from $13.5 \mathrm{dpc}$ embryos and its receptor, c-met, is expressed in the newly formed cords of embryos of the same age (Ricci et al. 1999). In the present paper, we report the expression of HGF and its receptor during the fetal period of the prenatal development of the testis and we demonstrate that the HGF receptor is expressed in the testis during this period of development. Interestingly, we found that the expression pattern of c-met is developmentally regulated. We demonstrate that, as during the early stages of testicular morphogenesis (Ricci et al. 1999), at $15.5 \mathrm{dpc}$ the receptor is expressed in the cells of the cords, whereas during the last days of prenatal testis development c-met is almost exclusively expressed by the interstitial cells. We tried to understand in which cell type the receptor is expressed. To this purpose the detection of both c-met and relaxin, a molecule specifically expressed in the fully developed Leydig cells, was performed 

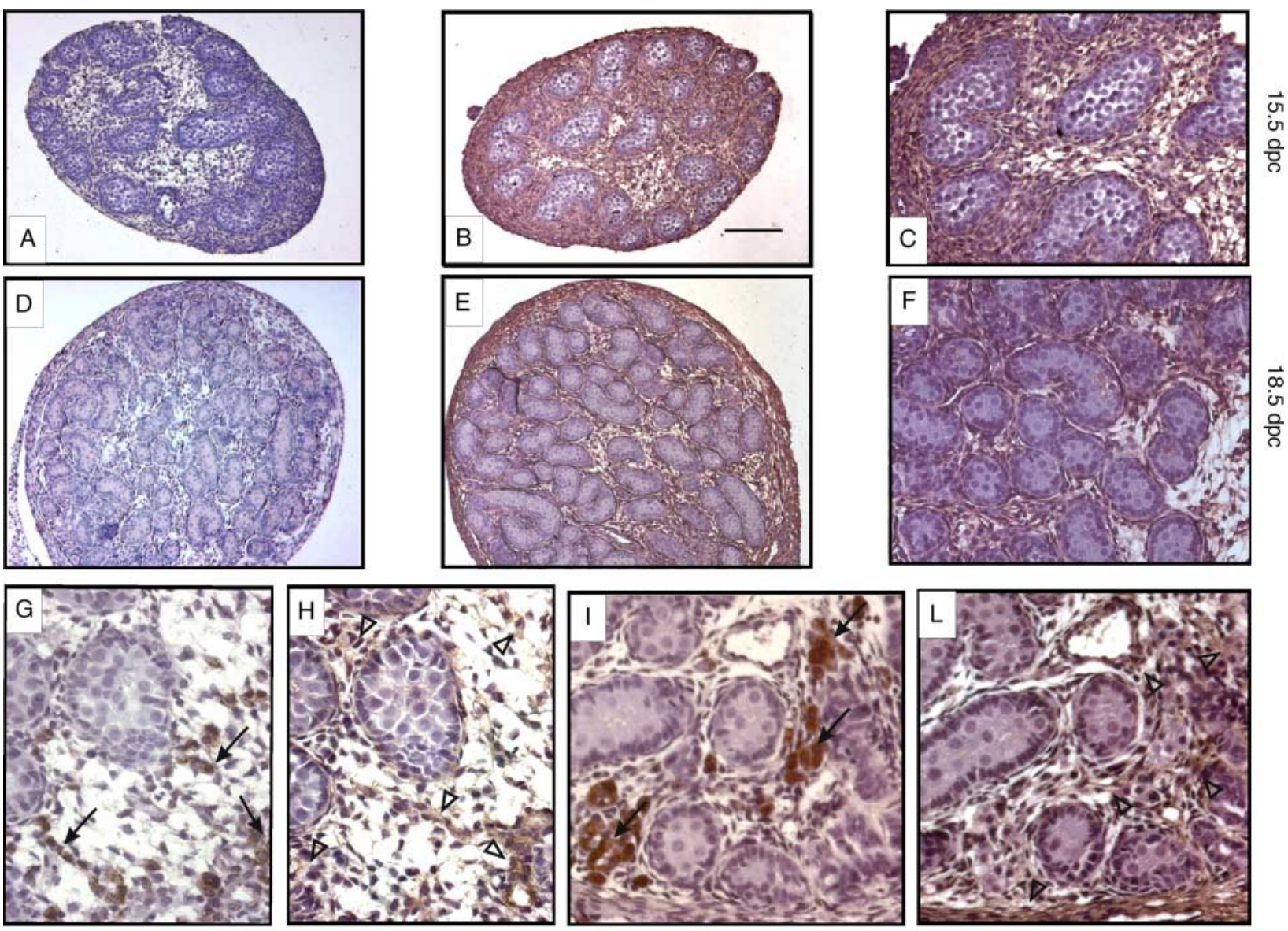

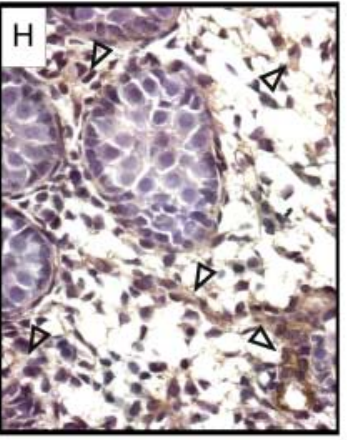

$15.5 \mathrm{dpc}$
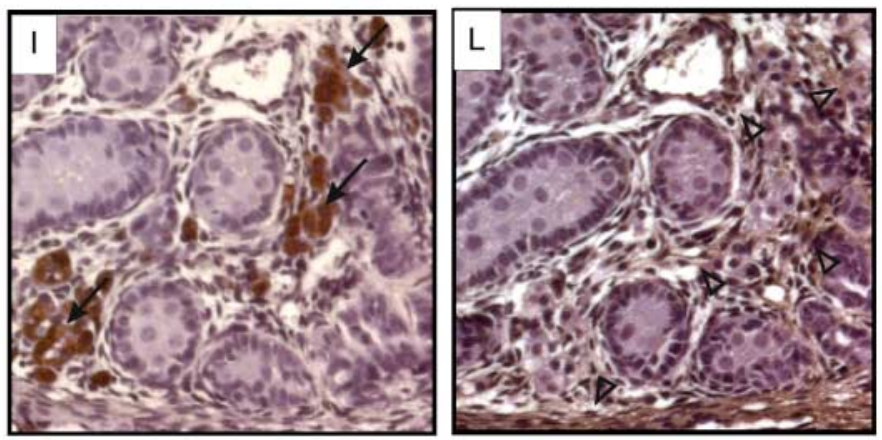

$18.5 \mathrm{dpc}$

Figure 5 Immunohistochemical localization of HGF in the testis isolated from $15.5 \mathrm{dpc}(\mathrm{B}, \mathrm{C}, \mathrm{H})$ and $18.5 \mathrm{dpc}(\mathrm{E}, \mathrm{F}, \mathrm{L})$ embryos. Low and high magnification of the samples is reported. The positivity is localized in the tunica albuginea cells, in the interstitial compartment and in the peritubular cells. In (A) and (D) negative control sections of one of the three experiments performed are presented. In $(G)$ and $(H)($ serial sections of $2.5 \mu \mathrm{m})$, the localization of $3 \beta-\mathrm{HSD}(\mathrm{G}$, arrows) and HGF ( $\mathrm{H}$, arrowheads) in $15.5 \mathrm{dpc}$ testes is reported. In I and $\mathrm{L}$, serial sections from $18.5 \mathrm{dpc}$ testes are shown. In (I), the arrows indicate the $3 \beta$-HSD-positive cells. In (L), the arrowheads indicate the HGFpositive cells. The bar value is $150 \mu \mathrm{m}$ in $\mathrm{A}, \mathrm{B}, \mathrm{D}, \mathrm{E}, 65 \mu \mathrm{m}$ in $\mathrm{C}, \mathrm{F}$, and $38 \mu \mathrm{m}$ in $\mathrm{G}, \mathrm{H}, \mathrm{I}, \mathrm{L}$.

on serial sections of $18.5 \mathrm{dpc}$ testes. The detection of both molecules on the same cell type indicates that fetal Leydig cells express c-met and, presumably, are target cells for HGF action.

We also studied the expression of HGF during the last part of gestation and we report that HGF is expressed in the developing gonads and its expression is localized in the interstitial compartment of the testis from both 15.5 and 18.5 dpc embryos. The localization of HGF and a molecule specifically expressed in the Leydig cells (such as $3 \beta-\mathrm{HSD}$ ) on serial sections of testes of both ages, allows us to demonstrate that Leydig cells do not express HGF. This indicates that in the interstitial compartment of the embryonic testis, HGF is produced by a cell type different from Leydig cells and exerts a paracrine action on the Leydig cells. We have recently shown a similar paracrine action of HGF in the seminiferous tubules of the postnatal testis in which HGF is produced by the myoid cells and increases the expression levels of c-met in the Sertoli cells (Catizone et al. 2005).

As well demonstrated, HGF is a pleiotropic cytokine able to induce multiple biological activities in different cell types (Matsumoto \& Nakamura 1993, Zarnegar \& Michalopoulos 1995, Trusolino et al. 1998), playing different roles during embryonic development and mediating essential interactions between mesenchymal and epithelial cells (Birchmeier \& Gherardi 1998). The ability of HGF in inducing the morphogenesis of different epithelial cells, such as mammary gland and prostate cells, is also well documented (Brinkmann et al. 1995). Our previous papers have outlined some of the roles of HGF during the early differentiation of the male gonad, that is during the formation of the testicular cords (Ricci et al. 1999, 2002). We now report that at $18.5 \mathrm{dpc}$, HGF is produced in the interstitial compartment of the testis and that the HGF receptor, c-met, is expressed in the Leydig 

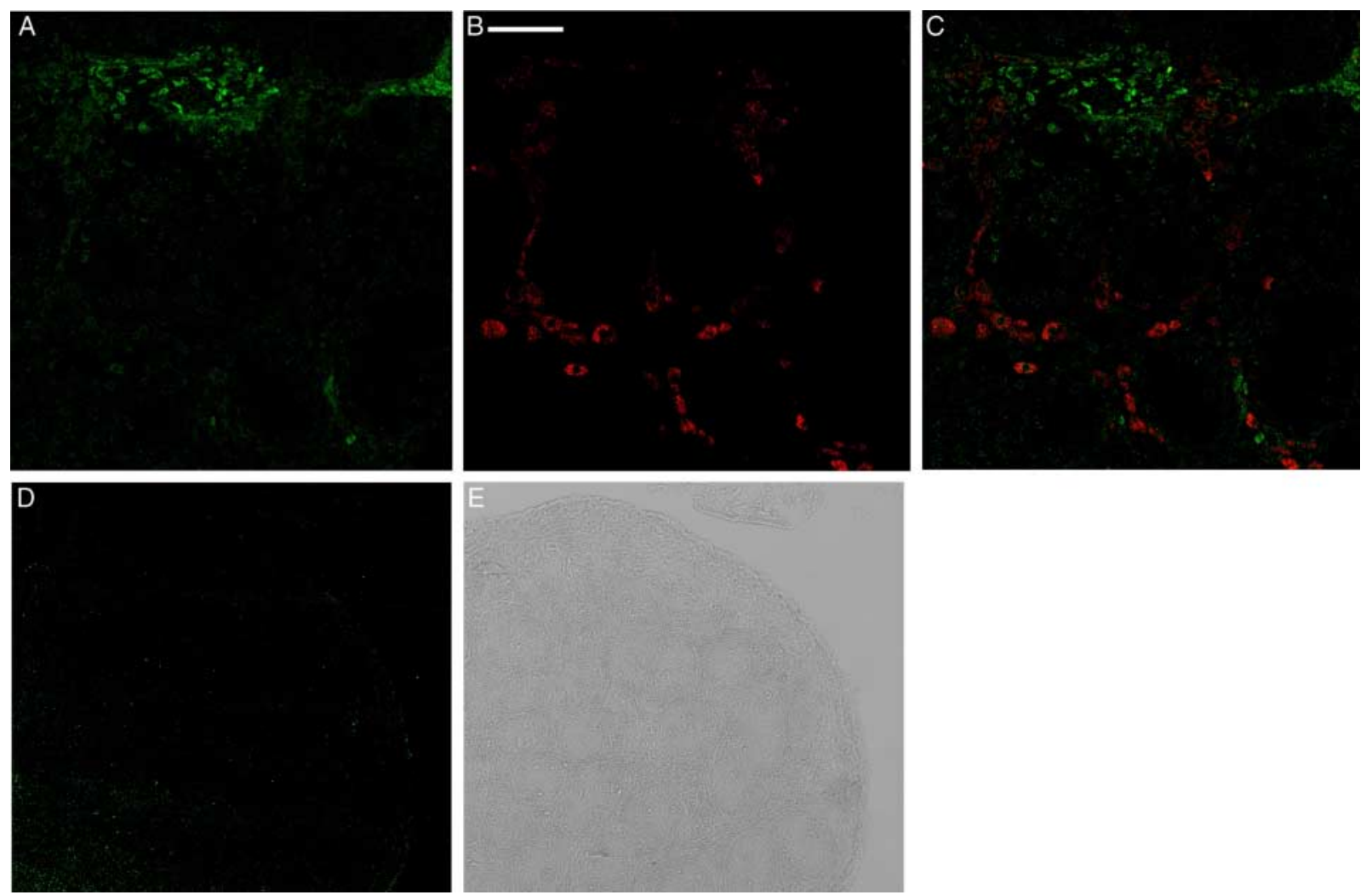

Figure 6 Confocal analysis of a single optical slice of testis from $18.5 \mathrm{dpc}$ embryo. The section was stained for HGF (A, green) and $3 \beta-H S D(B, r e d)$. In $(C)$, the merge of both images is presented. In (D), the picture obtained utilizing the anti-HGF antibody previously incubated with the human recombinant HGF is shown. In (E), the corresponding bright field is reported. The bar value is $35 \mu \mathrm{m}$ in $\mathrm{A}, \mathrm{B}, \mathrm{C}$ and $68 \mu \mathrm{m}$ in $\mathrm{D}, \mathrm{E}$.

cells. Testosterone secretion is the main functional activity of Leydig cells and it starts during the embryonic development of the testis as soon as Leydig cell differentiation occurs, i.e. $12 \cdot 5 \mathrm{dpc}$ (Taketo et al. 1991). For this reason, trying to evidence at least one of the effects of HGF on Leydig cell metabolic activities, we evaluated the amount of testosterone produced by the testes cultured in the absence or in the presence of HGF. Our results indicate that this fundamental functional parameter of Leydig cells is positively influenced by HGF. Interestingly, the increase of testosterone secretion is evident only when entire testes are cultured. Culturing dissociated testicular cells in the same cultural conditions (Pesce et al. 1994), the effect of HGF is not evident (not shown). This phenomenon is relevant for the researchers and could be ascribed to a different physiology of the Leydig cells detached from the other interstitial cells or by the loss of the molecular messages normally present in the interstitial compartment of the testis. The factors required for Leydig cell development are at the moment incompletely understood. DHH, a factor secreted by the Sertoli cells, is involved in the fetal Leydig cell differentiation (Yao et al. 2002) as well as PDGFR $\alpha$ (Brennan et al. 2003). In the present paper, we demonstrate that HGF is a paracrine factor for the interstitial compartment of the embryonic testis and regulates Leydig cell metabolic activity. We consider our results to be of great interest and we plan to investigate in the near future the possible roles of HGF on the regulation of fetal Leydig cell differentiation. It will also be interesting to investigate if HGF has a proliferative role during the late part of the embryonic development. It is known that the increase in size of the embryonic testis essentially happens during the initial part of testis development (Mittwoch et al. 1969) and we have previously reported that in the same period HGF acts as a mitogenic factor inducing proliferation of testicular cells (Ricci et al. 2002).

In conclusion, we have demonstrated that during the fetal period of pregnancy c-met expression is localized in the interstitial tissue of the testis, in particular in the Leydig cells and, in the same period, HGF is expressed in the interstitial compartment of the testis but not in the Leydig cells. Interestingly, we demonstrate that HGF influences the amount of testosterone secreted by testes of $18.5 \mathrm{dpc}$. Taken 

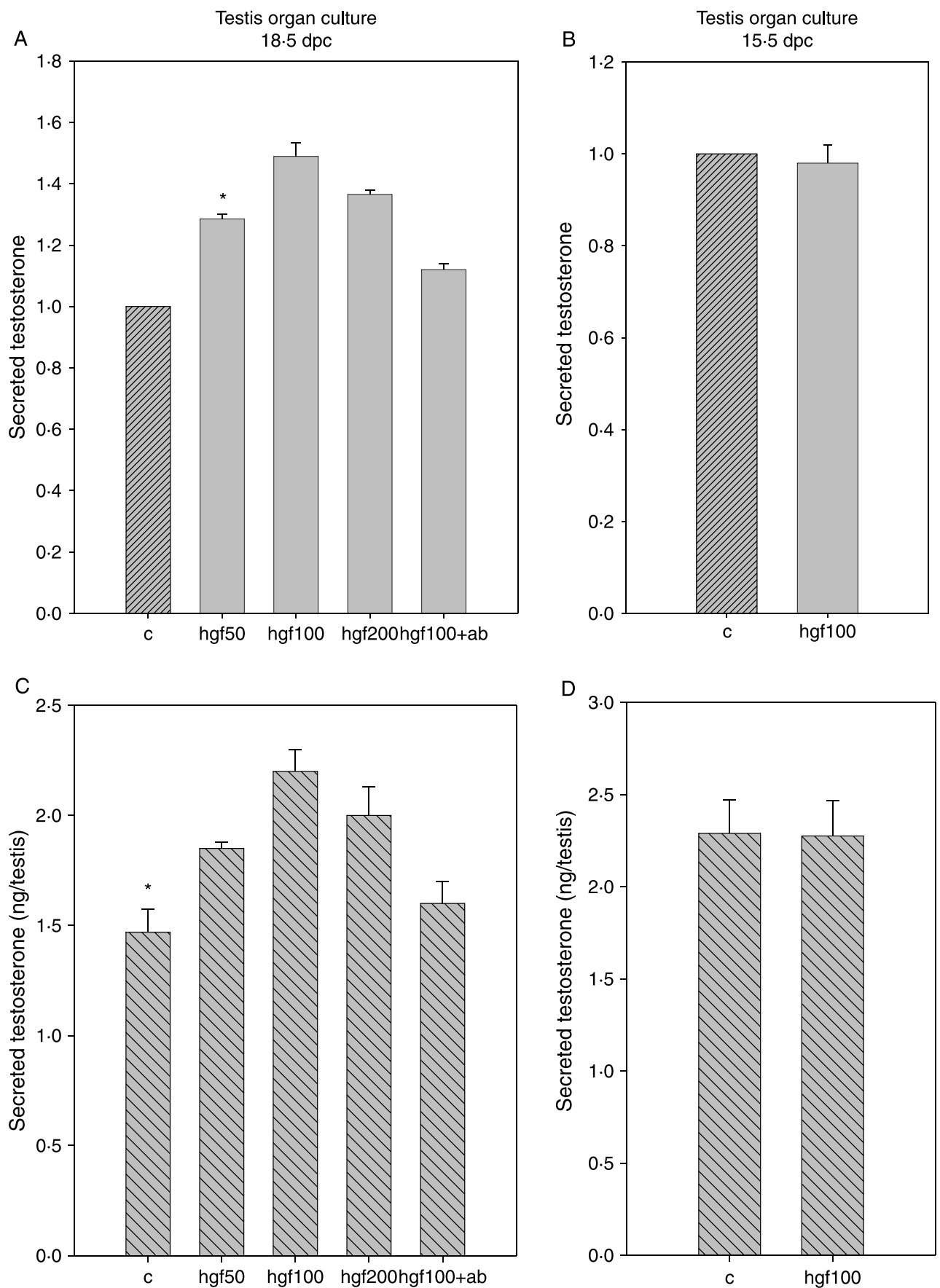

Figure 7 (A) Testosterone production of testes isolated from $18.5 \mathrm{dpc}$ embryos and cultured for $24 \mathrm{~h}$ in the presence of HGF (50$200 \mathrm{U} / \mathrm{ml}$ ) or control medium (C). In A and B, the results (mean \pm s.E.M.) of the four experiments, each performed in triplicate, are reported. The data are expressed considering the level of testosterone produced by the 'control' samples as ' 1 '. The values of the samples treated with HGFare reported as percentage increase with respect to the control values. ${ }^{*} P<0 \cdot 05$, vs $100,200,100+$ ab. The percentage increase of HGF 100 vs HGF 200 is not statistically significant. (B) Testosterone production of testes isolated from $15 \cdot 5 \mathrm{dpc}$ embryos and cultured for $24 \mathrm{~h}$ in the presence of HGF $(100 \mathrm{U} / \mathrm{ml})$ or control medium (C). The results (mean \pm S.E.M.) of the three experiments, each performed in triplicate, are reported. The data are expressed considering the level of testosterone produced by the 'control' samples as ' 1 '. The values of the HGF-treated samples are reported as percentage increase with respect to the control values. The significance of the results was determined by using the Student $t$-test. (C) and (D) absolute values obtained in one representative experiment performed utilizing 18.5 and $15 \cdot 5$ dpc testes are reported. ${ }^{*} P<0 \cdot 05$ vs $50,100,200 ;{ }^{*} P$, vs HGF $100+$ ab not significant. 
together, our data reveal a new role of HGF during embryonic testis development and confirm that the $\mathrm{HGF} / \mathrm{c}-\mathrm{met}$ system has a relevant role in the development of the mammalian testis.

\section{Acknowledgements}

The authors wish to thank Dr C Ponzetto (Torino Unversity) for c-DNA probe, Dr M Prat (Piemonte Orientale University) for anti-HGF antibody, Dr R Ivell (Institute of Hormone and Fertility Research, Hamburg) for the antirelaxin antibody, and Dr J I Mason (University of Edinburgh) for the anti-3 $\beta$-HSD antibody. Contract grant sponsor: Italian Ministero per l'Università e la Ricerca Scientifica e Tecnologica. Contract grant number: M.U.R.S.T., Cofin 2002 to M G. The authors declare that there is no conflict of interest that would prejudice the impartiality of this scientific work.

\section{References}

Birchmeier C \& Gherardi E 1998 Developmental roles of HGF/SF and its receptor, the c-Met tyrosine kinase. Trends in Cell Biology 8 404-410.

Brennan J, Tilmann C \& Capel B 2003 Pdgfr-alpha mediates testis cord organization and fetal Leydig cell development in the XY gonad. Genes and Development 17 800-810.

Brinkmann V, Foroutan H, Sachs M, Weidner M \& Birchmeier W 1995 Hepatocyte growth factor/scatter factor induces a variety of tissue-specific morphogenic programs in epithelial cells. Journal of Cell Biology 131 1573-1586.

Buehr M, Gu S \& McLaren A 1993 Mesonephric contribution to testis differentiation in the fetal mouse. Development 117 273-281.

Capel B, Albrecht KH, Washburn LL \& Eicher EM 1999 Migration of mesonephric cells into the mammalian gonad depends on Sry. Mechanisms of Development 84 127-131.

Catizone A, Ricci G \& Galdieri M 2005 HGF and postnatal testis development. Molecular and Cellular Endocrinology 241 32-40.

Chomczynski P \& Sacchi N 1987 Single-step method of RNA isolation by acid guanidinium thiocyanate-phenol-chloroform extraction. Analytical Biochemistry 162 156-159.

Cupp AS, Kim G \& Skinner MK 1999a Expression and action of transforming growth factor beta (TGFbeta1, TGFbeta2, and TGFbeta3) during embryonic rat testis development. Biology of Reproduction 60 1304-1313.

Cupp AS, Dufour JM, Kim G, Skinner MK \& Kim KH 1999b Action of retinoids on embryonic and early postnatal testis development. Endocrinology $1402343-2352$.

Cupp AS, Kim GH \& Skinner MK 2000 Expression and action of neurotropin-3 and nerve growth factor in embryonic and early postnatal rat testis development. Biology of Reproduction 63 1617-1628.

Cupp AS, Tessarollo L \& Skinner MK 2002 Testis developmental phenotypes in neurotropin receptor trkA and trkC null mutations: role in formation of seminiferous cords and germ cell survival. Biology of Reproduction 66 $1838-1845$.

Jeays-Ward K, Hoyle C, Brennan J, Dandonneau M, Alldus G, Capel B \& Swain A 2003 Endothelial and steroidogenic cell migration are regulated by WNT4 in the developing mammalian gonad. Development $1303663-3670$.
Karl J \& Capel B 1998 Sertoli cells of the mouse testis originate from the coelomic epithelium. Developmental Biology 203 323-333.

Levine E, Cupp AS, Miyashiro L \& Skinner MK 2000 Role of transforming growth factor-alpha and the epidermal growth factor receptor in embryonic rat testis development. Biology of Reproduction 62 477-490.

Martineau J, Nordqvist K, Tilmann C, Lovell-Badge R \& Capel B 1997 Male-specific cell migration into the developing gonad. Current Biology 7 958-968.

Matsumoto K \& Nakamura T 1993 Roles of HGF as a pleiotropic factor in organ regeneration. EXS 65 225-249.

Mittwoch U, Delhanty JD \& Beck F 1969 Growth of differentiating testes and ovaries. Nature 224 1323-1325.

Nef S, Verma-Kurvari S, Merenmies J, Vassalli JD, Efstratiadis A, Accili D \& Parada LF 2003 Testis determination requires insulin receptor family function in mice. Nature 426 291-295.

Olaso R, Pairault C, Boulogne B, Durand P \& Habert R 1998 Transforming growth factor beta1 and beta 2 reduce the number of gonocytes by increasing apoptosis. Endocrinology 139 733-740.

Pesce M, Siracusa G, Giustiniani Q \& De Felici M 1994 Histotypic in vitro reorganization of dissociated cells from mouse fetal gonads. Differentiation $\mathbf{5 6}$ 137-142.

Puglianiello A, Campagnolo L, Farini D, Cipollone D, Russo MA \& Siracusa G 2004 Expression and role of PDGF-BB and PDGFR-beta during testis morphogenesis in the mouse embryo. Journal of Cell Science 117 1151-1160.

Ricci G, Catizone A, Innocenzi A \& Galdieri M 1999 Hepatocyte growth factor (HGF) receptor expression and role of HGF during embryonic mouse testis development. Developmental Biology 216 340-347.

Ricci G, Catizone A \& Galdieri M 2002 Pleiotropic activity of hepatocyte growth factor during embryonic mouse testis development. Mechanisms of Development 118 19-28.

Ricci G, Catizone A \& Galdieri M 2004 Embryonic mouse testis development: role of platelet derived growth factor (PDGF-BB). Journal of Cellular Physiology 200 458-467.

Taketo T, Saeed J, Roberge S, Matsuo N \& Koide SS 1991 Regulation of testicular differentiation and testosterone production in the fetal mouse gonad in vitro. Journal of Steroid Biochemistry and Molecular Biology $\mathbf{3 8}$ 523-531.

Tilmann C \& Capel B 1999 Mesonephric cell migration induces testis cord formation and Sertoli cell differentiation in the mammalian gonad. Development 126 2883-2890.

Trusolino L, Pugliese L \& Comoglio PM 1998 Interactions between scatter factors and their receptors: hints for therapeutic applications. FASEB Journal 12 1267-1280.

Uzumcu M, Westfall SD, Dirks KA \& Skinner MK 2002 Embryonic testis cord formation and mesonephric cell migration requires the phosphotidylinositol 3-kinase signaling pathway. Biology of Reproduction 67 1927-1935.

Wilkinson DG \& Nieto MA 1993 Detection of messenger RNA by in situ hybridization to tissue sections and whole mounts. Methods in Enzymology 225 361-373.

Yao HH, Whoriskey W \& Capel B 2002 Desert Hedgehog/Patched 1 signaling specifies fetal Leydig cell fate in testis organogenesis. Genes and Development 16 1433-1440.

Zarnegar R \& Michalopoulos GK 1995 The many faces of hepatocyte growth factor: from hepatopoiesis to hematopoiesis. Journal of Cell Biology 129 $1177-1180$.

Received in final form 27 July 2006

Accepted 28 September 2006 